\title{
Economic costs of hospitalized diarrheal disease in Bangladesh: a societal perspective
}

\author{
Abdur Razzaque Sarker ${ }^{1,2 *}$, Marufa Sultana', Rashidul Alam Mahumud ${ }^{1}$, Nausad Ali ${ }^{1}$, Tanvir M Huda ${ }^{1,3}$, \\ M. Salim uzzaman ${ }^{4}$, Sabbir Haider ${ }^{5}$, Hafizur Rahman ${ }^{5}$, Ziaul Islam¹, Jahangir A. M. Khan ${ }^{6}$, Robert Van Der Meer ${ }^{2}$ \\ and Alec Morton ${ }^{2}$
}

\begin{abstract}
Background: Diarrheal diseases are a major threat to human health and still represent a leading cause of morbidity and mortality worldwide. Although the burden of the diarrheal diseases is much lower in developed countries, it is a significant public health problem in low and middle-income countries like Bangladesh. Though diarrhea is preventable and managed with low-cost interventions, it is still the leading cause of morbidity according to the patient who sought care from public hospitals in Bangladesh indicating that significant resources are consumed in treating those patients. The aim of the study is to capture the inpatients and outpatient treatment cost of diarrheal disease and to measure the cost burden and coping mechanisms associated with diarrheal illness.
\end{abstract}

Methods: This study was conducted in six randomly selected district hospitals from six divisions (larger administrative units) in Bangladesh. The study was performed from the societal perspective which means all types of costs were identified, measured and valued no matter who incurred them. Cost analysis was estimated using the guideline proposed by the World Health Organization for estimating the economic burden of diarrheal diseases. The study adopted quantitative techniques to collect the household and hospital level data including structured and semi-structured questionnaires, observation checklists, analysis of hospital database, telephone interviews and compilation of service statistics.

Results: The average total societal cost of illness per episode was BDT 5274.02 (US \$ 67.18) whereas the average inpatient and outpatient costs were BDT 8675.09 (US $\$ 110.51$ ) and BDT 1853.96 (US $\$ 23.62$ ) respectively. The cost burden was significantly highest for poorest households, $21.45 \%$ of household income, compared to $4.21 \%$ of the richest quintile.

Conclusions: Diarrheal diseases continue to be an overwhelming problem in Bangladesh. The economic impact of any public health interventions (either preventive or promotive) that can reduce the prevalence of diarrheal diseases can be estimated from the data generated from this study.

Keywords: Bangladesh, Catastrophic expenditure, Cost-of-illness, Diarrhea, Out-of-pocket payment, Public hospitals

\section{Background}

Diarrheal diseases are a global public health problem and a leading cause of morbidity and mortality across the world. According to the latest Global Burden of Disease Study, about 2.39 billion of diarrheal cases occurred globally and approximately 0.53 million of under five children died every

\footnotetext{
* Correspondence: arazzaque@icddrb.org

${ }^{1}$ International Centre for Diarrhoeal Disease Research, Bangladesh (icddr,b), Dhaka, Bangladesh

${ }^{2}$ University of Strathclyde, Glasgow, UK

Full list of author information is available at the end of the article
}

year $[1,2]$. Specifically, incidence and case-fatality ratios are much higher in lower and middle income (LMI) countries [3]. In Bangladesh, diarrhea diseases are still very common among children under 5 years old [4]. In developing countries, diarrhea-related morbidity and mortality is directly linked with limited access to potable water and proper sanitation system [5]. Several studies observed that epidemics of diarrheal disease are associated with episodes of flooding [6], socioeconomic status [7], urban status [8] high population density, low education level and the proximity of household clusters to contaminated surface water [9-11]. 
The diseases are highly sensitive to climate, showing seasonal variations in numerous sites [12]. Relative humidity and temperature influence the rate of replication of different types of pathogens such as bacteria and protozoa, and also the survival of enteroviruses in the environment which is another cause of diarrheal diseases [13]. Diarrhea is an alteration in normal bowel movement characterized by an increase in water content, volume, or frequency of stools [14]. If the disease lasts "more than 7 days" and "at least 14 days" the term "prolonged" and "persistent" diarrhea is used respectively $[15,16]$.

Though diarrhea is preventable and managed with lowcost interventions, it is still the top cause of morbidity for patients who sought care from the public hospital system in Bangladesh [17] and significant resources are expended in treating these patients. Diarrheal diseases affect people of all ages irrespective of their socio-economic status and are particularly prevalent among poor people. A significant cause for concern in Bangladesh is that approximately $26 \%$ of the people are below the poverty datum line. In some cases, the episode can be managed at home and does not require hospital treatment. However, considering the direct and indirect cost of households, it represents a substantial economic burden for the affected households [18].

There are several studies about the economic burden of diarrheal disease in many countries [19-25] but knowledge about the treatment cost of a full diarrheal episode is still limited in Bangladesh although such studies are vital for informing policies and allowing international comparisons $[26,27]$. There are several economic studies are available focusing diarrheal diseases in Bangladesh [28-31]. Nevertheless, these studies did not consider the societal perspective to capture the average cost for diarrheal treatment. However, it is essential for policy makers to understand the precise estimate of the economic cost of diarrheal treatment based on uniform methodologies for setting priorities for health sector as well as for balanced allocation of scarce resources. The intent of this study is to estimate the age and sex specific economic costs of diarrheal disease considering a broad social perspective and to capture the healthcare seeking pattern during the diarrheal episode in Bangladesh.

\section{Methods}

\section{Study setting and sample}

This study was conducted in public district hospitals in Bangladesh. Public hospitals play a major role in providing treatment for a relatively large population as the treatment cost in public hospitals is less than private for-profit hospitals and hospitals financed by nongovernmental organisations (NGOs). A total of 801 diarrheal patients were randomly selected and interviewed from January to December 2015.

\section{Study perspective}

The study was a societal perspective which means all types of costs were identified, measured and valued no matter who incurred them. The societal perspective is the summation of provider and household perspective which is recommended in the current standards for cost-effectiveness analysis methods [32,33].

\section{Cost estimates}

Cost analysis was estimated using the guideline proposed by the World Health Organization (WHO) for estimating the economic burden of diarrheal diseases [34]. A bottomup micro-costing approach was used to generate the cost of illness per episode per patient where all relevant cost components are identified and valued at the most detailed level $[34,35]$.

To capture the household economic cost of illness both direct and indirect costs were captured. Direct costs were defined as expenditure during treatment by households which consists of two parts: direct medical cost and direct non-medical cost. Direct medical expenses include those costs consumed for healthcare resources during diarrheal episodes such as medicine, diagnosis, registration fees and others. The direct non-medical cost includes transportation, lodging, food items, informal payment, payment for helping the patients during treatment. There are other types of expenditure such as material costs like a mug, jar, plate, glass and other items such as a coil, lighter and other cost items of patients, as well as expenditure for people accompanying the patients and their caregivers to stay outside of hospitals during diarrheal treatment.

The indirect cost was considered the income loss as well as productivity loss because of travel to the health centre and costs due to absence from work because of illness related to the diarrheal disease. Self-reported wage rates were used for estimating the income loss. Productivity costs were estimated using a human capital approach which reflected the value of all unpaid time devoted to caregiving themselves, as well as family members and friends [36]. The inclusion of caregiving time based on the assumption that time dedicated to caregiving may represent foregone non-market activities such as school, household chores, child care, and leisure or domestic work [37, 38]. This time comprised time spent directly on patient care (by the patient and by unpaid attendants or caregivers), such as attending to diarrhea-related health care appointments. To capture the productivity losses for non-market activities, we used the age-specific and occupation-specific wage rates $[38,39]$. We used age-specific wages for adults, teenagers and children aged 5 to 14 years, where the minimum salary rate according to national level was given by the adult patients, one-half for the teenagers and three-quarters to capture productivity loss for children, however, half of the 
average salary rate assigned to unpaid home workers considering their age group $[38,39]$. Intangible or psychic costs such as costs related to suffering and grief were not measured in this study as those costs are not valued in the disease-specific cost of illness research [38, 40]. Again, time cost of visitor and extra irregular expense borne by the patients, caregivers, and visitors on their way during the time of hospitalization were not included in the analysis. The household cost burden measured by the percentage of total household earnings that was consumed by the treatment cost of diarrheal diseases [41].

The average treatment costs for diarrheal diseases borne by the public hospitals were measured using the patientspecific treatment costs approach according to WHO guidelines [34]. In this aspect, average outpatients and inpatients visits costs were estimated. The costs included costs of diagnosis, laboratory cost, medicine costs, feeding costs, institutional cost and other associated costs borne by the hospitals for treating on a patient-specific basis. Shared costs were allocated according to the number of patient's days of hospitalization. Capital cost was annuitized with 3\% discount rate [35]. The provider actual cost of illness calculated the provider's cost for treatment devoid of any fees received from the patients for hospitalization, drug, diagnostic tests, etc. Finally, the societal cost of illness was estimated by adding provider's actual cost of illness per patients with the cost incurred per household.

\section{Method of data collection}

The study adopted quantitative techniques to collect the household and hospital level data including the structured questionnaire, observation checklist, hospital database, telephone interviews and compilation of service statistics. For household level, respondents were the adult patients or the accompanying person who was most familiar with the costs incurred during the treatment of the patient and interviews were conducted during discharge from the hospital. Patients' records drawn from the above Hospital Records Departments (HRD) were reviewed for the use of resources for diarrheal patients. Resource utilisation data were abstracted from the registers for inpatients or outpatients. At the central level, several offices such as finance, procurement and supply and maintenance unit were contacted to validate the cost information. A research assistant reviewed the patient's records, and data abstraction forms were updated daily until the discharge of the patient. Finally, a telephone interview was conducted for taking necessary information within 1 week after discharge from hospital. Caregivers were also interviewed in their language of preference with the use of a standardised interview schedule on admission or soon thereafter. Questions were asked regarding transportation, consultation before the hospital visit, medicine brought, expenses during the hospitalization, and losses of wages resulting from absence from work.

\section{Ethics approval}

The research protocol of this study was approved by the Institutional Review Board of the International Centre for Diarrheal Disease Research, Bangladesh (icddr,b). Informed consent was obtained from all respondents before data collection.

\section{Data analysis}

Completed questionnaires were developed by a qualified supervisor with both numerical and logical checks to minimise errors. Before analysis, missing answers and outliers were systematically verified. Patient specific cost of illness borne by the household and provider costs are reported separately. The data were analysed using a spreadsheet in Microsoft Excel and Stata/SE 13.0 (StataCorp. College Station, TX, USA). Proportion, frequencies, rates and ratio, were presented with a standard deviation in local currency, i.e., Bangladeshi Taka (BDT) and US dollars (US\$) applying the exchange rate (US $\$ 1=78.5 \mathrm{BDT}$ ) during the year of the survey mid 2014- mid 2015 [42]. Like the earlier study, to test the robustness of the assumption, a sensitivity analysis was conducted to examine the impact of potential outlier on the total cost of illness [43]. However, the cost of caregivers of households had a higher level of uncertainty [44]. For this purpose, we tested the effect of changes of $20 \%$ in the parameter values of both direct and indirect cost of households and $20 \%$ change of both medical and non-medical cost of the provider as performed in other studies $[38,45]$.

\section{Results}

\section{Background characteristics}

A total of 801 patients participated in the study from selected public district hospitals, among whom 402 and 399 patients were inpatients and outpatients respectively. All respondents participating in this survey were provided with information about the study, and none withheld consent. The average age of the patients were 15.46 years $(\mathrm{SD}=21.08$ years) of which $57.43 \%$ were age under 5 years followed by $24.34 \%$ for age ranged $15-45$ years. The highest percentage of patients were homemakers (38.12\%), students $(23.75 \%)$, self-employed $(14.37 \%)$ and only $9.09 \%$ of the patients were salaried employees. Approximately, $31 \%$ of the patients had up to secondary grade education, and primary school (29.64\%). Only $4.19 \%$ of the patients had higher level education whereas $18.56 \%$ had no formal education, and $11.08 \%$ had no education (Table 1). However, diarrheal occurrence was higher among households with lower parental levels of educational attainment (Table 1). It was also higher among households with up to 4 to 5 members (43.32\%) followed by more than five members $(38.83 \%)$, and the average patient's household size was 3.20 $(\mathrm{SD}=0.74)$ (Table 1). The average monthly income and expenditure of the household were BDT 19,603 (US\$ 249.72) and BDT 15,470 (US\$ 197.07) respectively while the average 
Table 1 Background characteristics of the study participants for public tertiary level hospital $(N=801)$

\begin{tabular}{|c|c|c|c|}
\hline Variables & Description & $\mathrm{n}(\%) /$ mean $\pm \mathrm{SD}$ & $95 \% \mathrm{Cl}$ (\% or mean) \\
\hline \multirow[t]{3}{*}{ Number of patients } & $\mathrm{N}$ & 801 & \\
\hline & Inpatient & $402(50.19)$ & $(46.72,53.65)$ \\
\hline & Outpatient & 399 (49.81) & $(46.35,53.28)$ \\
\hline \multirow[t]{5}{*}{ Patient age (\%) } & Up to 4 & $460(57.43)$ & $(53.09,59.96)$ \\
\hline & 5 to 14 & $55(6.87)$ & $(6.08,9.81)$ \\
\hline & 15 to 45 & $195(24.34)$ & $(21.49,27.44)$ \\
\hline & 46 to 60 & $62(7.74)$ & $(6.08,9.81)$ \\
\hline & $60+$ & $29(3.62)$ & $(2.53,5.17)$ \\
\hline \multirow[t]{6}{*}{ Patient age yrs. (mean \pm SD) } & Up to 4 & $1.41 \pm 0.96$ & $(1.32,1.50)$ \\
\hline & 5 to 14 & $8.12 \pm 2.76$ & $(7.38,8.87)$ \\
\hline & 15 to 45 & $29.08 \pm 9.43$ & $(27.74,30.41)$ \\
\hline & 46 to 60 & $55.47 \pm 4.3$ & $(54.38,56.56)$ \\
\hline & $60+$ & $75.03 \pm 11.99$ & $(70.47,79.6)$ \\
\hline & Overall & $15.46 \pm 21.08$ & $(13.99,16.92)$ \\
\hline \multirow[t]{2}{*}{ Gender (\%) } & Male & $404(50.44)$ & $(46.97,53.9)$ \\
\hline & Female & $397(49.56)$ & $(46.1,53.03)$ \\
\hline \multirow[t]{7}{*}{ Patient Occupation (\%) } & House wife & $130(38.12)$ & $(33.09,43.42)$ \\
\hline & Students & $81(23.75)$ & $(19.51,28.59)$ \\
\hline & Self-employment & $49(14.37)$ & $(11.02,18.53)$ \\
\hline & Unemployed & $7(2.05)$ & $(0.98,4.26)$ \\
\hline & Salaried employee & $31(9.09)$ & $(6.45,12.66)$ \\
\hline & Business & $18(5.28)$ & $(3.34,8.24)$ \\
\hline & Others & $25(7.33)$ & $(4.99,10.64)$ \\
\hline \multirow[t]{6}{*}{ Patient education level (\%) } & Illiterate & $37(11.08)$ & $(8.17,15.03)$ \\
\hline & No formal education & $62(18.56)$ & $(14.82,23.26)$ \\
\hline & Up to primary & $99(29.64)$ & $(24.55,34.36)$ \\
\hline & Secondary & $103(30.84)$ & $(26.26,36.23)$ \\
\hline & Higher secondary & $19(5.69)$ & $(3.67,8.82)$ \\
\hline & Higher & $14(4.19)$ & $(2.51,7.01)$ \\
\hline \multirow[t]{6}{*}{ Mother education level (\%) } & Illiterate & $156(19.48)$ & $(16.87,22.37)$ \\
\hline & formal education & $114(14.23)$ & $(11.98,16.83)$ \\
\hline & Up to primary & $199(24.84)$ & $(21.97,27.96)$ \\
\hline & Secondary & $274(34.21)$ & $(30.99,37.57)$ \\
\hline & Higher secondary & $37(4.62)$ & $(3.36,6.31)$ \\
\hline & Higher & $21(2.62)$ & $(1.71,3.99)$ \\
\hline \multirow[t]{6}{*}{ Father education level (\%) } & Illiterate & $139(17.35)$ & $(14.88,20.14)$ \\
\hline & No formal education & $139(17.35)$ & $(14.88,20.14)$ \\
\hline & Up to primary & $191(23.85)$ & $(21.01,26.93)$ \\
\hline & Secondary & $241(30.09)$ & $(27,33.36)$ \\
\hline & Higher secondary & 49 (6.12) & $(4.65,8.01)$ \\
\hline & Higher & $42(5.24)$ & $(3.9,7.02)$ \\
\hline \multirow[t]{3}{*}{ Household size (\%) } & Less than 2 & $6(0.75)$ & $(0.34,1.66)$ \\
\hline & 2 to 3 & $137(17.1)$ & $(14.65,19.88)$ \\
\hline & 4 to 5 & 347 (43.32) & $(39.92,46.79)$ \\
\hline
\end{tabular}


Table 1 Background characteristics of the study participants for public tertiary level hospital $(N=801)$ (Continued)

\begin{tabular}{|c|c|c|c|}
\hline Variables & Description & $\mathrm{n}(\%) /$ mean $\pm \mathrm{SD}$ & $95 \% \mathrm{Cl}$ (\% or mean) \\
\hline & More than 5 & $311(38.83)$ & $(35.5,42.26)$ \\
\hline Household size & & $3.20 \pm 0.74$ & $(3.15,3.25)$ \\
\hline Patient monthly income, BDT $(n=411)$ & & $3976.78 \pm 8397.02$ & $(2974.40,4979.16)$ \\
\hline Monthly income of household (BDT) & & $19,603.37 \pm 26,641.74$ & $(17,755.58,21,451.16)$ \\
\hline Monthly expenditure of household (BDT) & & $15,469.69 \pm 10,702$ & $(14,727.43,16,211.94)$ \\
\hline Overall healthcare expenditure last 3 months (BDT) & & $5191.43 \pm 17,745.43$ & $(3960.66,6422.20)$ \\
\hline \multicolumn{4}{|l|}{ Income quintile (BDT) } \\
\hline Poorest quintile $(\leq 10,000 \mathrm{BDT})$ & & $7963.77 \pm 2025.22$ & $(7723.785,8203.75)$ \\
\hline 2nd quintile $(10,001-12,000)$ & & $11,920.73 \pm 266.08$ & $(11,862.27,11,979.20)$ \\
\hline 3rd quintile $(12,001-18,000)$ & & $15,227.71 \pm 1253.44$ & $(15,035.63,15,419.80)$ \\
\hline 4th quintile $(18,001-30,000)$ & & $23,540.11 \pm 4014.05$ & $(22,961.02,24,119.20)$ \\
\hline Upper quintile $(30,000+)$ & & $62,188.89 \pm 62,881.18$ & $(49,018.68,75,359.10)$ \\
\hline
\end{tabular}

household healthcare expenditure in the previous 3 months was BDT 5191 (US\$ 66.13) (Table 1).

\section{Distribution of average household cost of illness}

Table 2 shows the average cost of illness per diarrheal episode from the household's perspective. The average total costs for treating the diarrhea patients were BDT 4178.68 (US \$ 53.23). The average total out-of-pocket (OOP) cost was BDT 1688.17 (US \$ 21.51) which represented $40 \%$ of the total household cost; where $28 \%$ was the direct medical and $12.41 \%$ was the direct non- medical cost. For OOP costs, medicine was the highest cost driver (BDT 1064.19 or US \$13.56) followed by non-medical transportation cost (BDT 246.58 or US\$ 3.14). Among the direct medical costs, diagnostic costs (BDT 37.63 or US\$ 0.48) and consultation fee (BDT 26.37 or US $\$ 0.34$ ) were the two most significant cost driver during the episode. However, caregivers expenditure (BDT 127.87 or US \$1.63) was the critical cost component of direct non-medical costs, which included transportation, food, mobile bill and other related expenses borne by the caregivers during the episodes of

Table 2 Distribution of average household cost of diarrheal treatment for tertiary level hospital $(N=801)$ BDT (US\$)

\begin{tabular}{|c|c|c|c|c|}
\hline \multirow[t]{2}{*}{ Cost } & \multirow[t]{2}{*}{ Parameter } & \multicolumn{2}{|c|}{ Overall cost of treatment } & \multirow[t]{2}{*}{ Proportion of total cost } \\
\hline & & Average & SD & \\
\hline \multirow[t]{6}{*}{ Direct Medical } & Diagnostic & $37.63(0.48)$ & $189.71(2.42)$ & 28 \\
\hline & Medicine & $1064.19(13.56)$ & $1427.04(18.18)$ & \\
\hline & Consultant fee & $26.37(0.34)$ & $121.38(1.55)$ & \\
\hline & Registration/admission fee & $14.54(0.19)$ & $11.42(0.15)$ & \\
\hline & Medical materials (syringe/cannula etc) & $27.32(0.35)$ & $62.43(0.80)$ & \\
\hline & Bed/ Cabin charge & $0.28(0.00)$ & $7.95(0.10)$ & \\
\hline \multirow[t]{7}{*}{ Direct Non-Medical } & Transportation cost & $246.58(3.14)$ & $427.76(5.45)$ & 12.41 \\
\hline & Food items & $113.82(1.45)$ & $239.77(3.05)$ & \\
\hline & Informal payment & $7.40(0.09)$ & $22.65(0.29)$ & \\
\hline & Caregiver's payment & $0.01(0.00)$ & $0.35(0.00)$ & \\
\hline & Materials (mug/glass etc.) & $22.65(0.29)$ & $70.59(0.90)$ & \\
\hline & Lodging & $0.00(0.00)$ & $0.01(0.00)$ & \\
\hline & Caregivers expenditure & $127.87(1.63)$ & $456.80(5.820$ & \\
\hline Total direct cost & & $1688.17(21.51)$ & $2010.95(25.62)$ & 40.4 \\
\hline \multirow[t]{2}{*}{ In-direct cost } & Patient income loss & $310.51(3.96)$ & $1374.40(17.51)$ & \\
\hline & Caregiver's income loss & $2179.50(27.76)$ & $3445.12(43.89)$ & \\
\hline Total indirect cost & & $2490.01(31.72)$ & $3881.48(49.45)$ & 59.6 \\
\hline Total cost & & $4178.68(53.23)$ & $5166.20(65.81)$ & 100 \\
\hline
\end{tabular}


diarrhea. For the indirect costs per episode (BDT 2490 or US \$ 31.72) caregivers income loss was the highest (BDT 2, 179.50 or US\$ 27.76), higher than patient's productivity loss (BDT 310.51 or US\$ 3.96).

\section{Household cost and associated variable}

Table 3 shows the association between the cost of illness and the variables of interest. The average household cost of illness was significant among the age groups. The average cost of illness (BDT 8407.58 or US\$ 107.1) for an elderly person was comparatively higher than any other age group. However, the cost of treating under 5 year old children were significantly lower (BDT 3440.66 or US \$ 43.83) than those aged more than 5 years (BDT 5173.09 or US\$ 65.90) $(P<0.001)$. The average cost of illness for male patients (BDT 4441.82 or US\$ 56.58) was higher than that of

Table 3 Association between household cost and other variables

\begin{tabular}{|c|c|c|c|c|c|}
\hline \multirow[t]{2}{*}{ Variables } & \multirow[t]{2}{*}{ Number of patients $(\mathrm{N})$} & \multicolumn{2}{|c|}{ Household cost, BDT (US \$) } & \multirow[t]{2}{*}{ t / F-statistic } & \multirow[t]{2}{*}{$P$-value } \\
\hline & & Average & SD & & \\
\hline \multicolumn{6}{|l|}{ Age group (years) } \\
\hline Up to 4 & 460 & $3440.66(43.83)$ & $4549.87(57.96)$ & \multirow[t]{5}{*}{$14.43^{\mathrm{a}}$} & \multirow[t]{5}{*}{$<0.0001$} \\
\hline 5 to 14 & 55 & $2483.17(31.63)$ & $3113.52(39.66)$ & & \\
\hline 15 to 45 & 195 & $4963.35(63.23)$ & $4766.65(60.72)$ & & \\
\hline 46 to 60 & 62 & $6706.05(85.43)$ & $8555.34(108.99)$ & & \\
\hline $60+$ & 29 & $8407.58(107.10)$ & $5987.61(76.28)$ & & \\
\hline \multicolumn{6}{|l|}{ Age group under five and others } \\
\hline Under 5 years old patients & 460 & $3440.66(43.83)$ & $4549.87(57.96)$ & \multirow[t]{2}{*}{$4.60^{\mathrm{b}}$} & \multirow[t]{2}{*}{$<0.0001$} \\
\hline More than 5 years old patients & 341 & $5173.09(65.90)$ & $5753.68(73.30)$ & & \\
\hline \multicolumn{6}{|l|}{ Sex } \\
\hline Male & 404 & $4441.82(56.58)$ & $5581.65(71.10)$ & \multirow[t]{2}{*}{$1.46^{\mathrm{b}}$} & \multirow[t]{2}{*}{0.14} \\
\hline Female & 397 & $3909.90(49.81)$ & $4696.13(59.82)$ & & \\
\hline \multicolumn{6}{|l|}{ Type of care } \\
\hline Inpatient care & 402 & $6570.79(83.70)$ & $5457.71(69.52)$ & \multirow[t]{2}{*}{$14.88^{b}$} & \multirow[t]{2}{*}{$<0.0001$} \\
\hline Outpatient care & 399 & $1767.58(22.52)$ & $3465.92(44.15)$ & & \\
\hline \multicolumn{6}{|l|}{ Income quintile } \\
\hline Poorest quintile $(\leq 10,000)$ & 276 & $3689.3(47.00)$ & $4412.93(56.22)$ & \multirow[t]{5}{*}{$0.28^{\mathrm{a}}$} & \multirow[t]{5}{*}{0.89} \\
\hline 2nd quintile $(10,001-12,000)$ & 82 & $4037.95(51.44)$ & $4785.6(60.96)$ & & \\
\hline 3rd quintile $(12,001-18,000)$ & 166 & $4202.38(53.53)$ & $4866.93(62.00)$ & & \\
\hline 4th quintile $(18,001-30,000)$ & 187 & $4453.03(56.73)$ & $5789.56(73.75)$ & & \\
\hline Upper quintile $(30,000+)$ & 90 & $5189.48(66.11)$ & $6549.86(83.44)$ & & \\
\hline \multicolumn{6}{|l|}{ For under 5 years old patients } \\
\hline \multicolumn{6}{|l|}{ Sex } \\
\hline Male & 248 & $3571.68(45.50)$ & $4566.33(58.17)$ & \multirow[t]{2}{*}{$0.67^{b}$} & \multirow[t]{2}{*}{0.505} \\
\hline Female & 212 & $3287.38(41.88)$ & $4536.52(57.79)$ & & \\
\hline \multicolumn{6}{|l|}{ Type of care } \\
\hline Inpatient care & 142 & $6770.96(86.25)$ & $4376.74(55.75)$ & \multirow[t]{2}{*}{$11.36^{\mathrm{b}}$} & \multirow[t]{2}{*}{$<0.0001$} \\
\hline Outpatient care & 318 & $1953.54(24.89)$ & $3777.22(48.12)$ & & \\
\hline \multicolumn{6}{|l|}{ Income quintile } \\
\hline Poorest quintile $(\leq 10,000)$ & 167 & $3499.31(44.58)$ & $4596.37(58.55)$ & $0.28^{\mathrm{a}}$ & 0.8919 \\
\hline 2nd quintile $(10,001-12,000)$ & 48 & $3835.03(48.85)$ & $5304.53(67.57)$ & & \\
\hline 3rd quintile $(12,001-18,000)$ & 94 & 3076.29 (39.19) & $3794.47(48.34)$ & & \\
\hline 4th quintile $(18,001-30,000)$ & 111 & $3554.23(45.28)$ & $5024.53(64.01)$ & & \\
\hline Upper quintile $(30,000+)$ & 40 & $3263.63(41.57)$ & $3697.33(47.10)$ & & \\
\hline
\end{tabular}


females (BDT 3909.9 or US\$ 49.81) and was not statistically significant $(P=0.505)$. Furthermore, the cost of illness for inpatient care was significantly $(P<0.001)$ higher (BDT 6570 or US $\$ 83.7$ ) than that of outpatient care (BDT 1767.58 or US $\$ 22.52)$.

\section{Cost burden and coping strategies}

The cost burden of diarrheal illness is presented in Table 4 and the 'total out of pocket costs' during treatment is shown as a percentage of the monthly earnings of the households. The OOP payment as a proportion of household income differed significantly among the income groups $(P<0.0001)$. It was observed that during the treatment course, the most common coping strategies were regular income (85.63\%) borrowing from others (15.63\%) and savings (9.38\%) (Fig. 1).

The overall OOP expenditure due to diarrheal treatment was $11.75 \%$ of monthly household income. However, in the poorest quintile, it exceeded $17 \%$ of the total household income. The richest (5th) quintile only spent $4.21 \%$ of their household income. Considering a 10\% threshold level, approximately $32 \%$ households suffered from catastrophic expenditure while the poorest quintile suffered more (49\%). Even at the highest threshold level of $25 \%$, the poorest $27 \%$ of households suffered from catastrophic expenditure due to diarrheal diseases (Table 4).

\section{Waiting and travel time}

Before coming to the selected public hospitals, most patients received treatment from other formal and informal care providers (Fig. 2). However, in LMI countries like Bangladesh, diarrheal patients are often inadequately treated at home. Homecare is associated with poor outcomes and timely medical treatment is the precondition to minimise the length of each episode and reduce mortality [46]. The average travel time to the public hospital was nearly $2 \mathrm{~h}$ and at least $30 \mathrm{~min}$ waiting time before being attended to.

\section{Inpatient and outpatient cost: Hospital perspective}

Table 5 shows the average total inpatient and outpatient treatment cost due to diarrheal disease. The average inpatient treatment cost per patient was BDT 2104.09 or US $\$ 26.80$ whereas direct medical costs constituted only $4.18 \%$. The total direct medical cost per diarrheal episode was BDT 88.27 or US \$ 1.12, and medicine cost was the largest (BDT 83.23 or US \$ 1.06). Among the direct non-medical costs staff salaries was a major cost driver (BDT 836.38 or US $\$ 10.65$ ) followed by capital costs (BDT 456.31 or US $\$ 5.81$ ). The other two larger cost components were food costs (BDT 323.25 or US \$ 4.12 ) and space for providing patient services (BDT 321.74 or 4.10$)$.

The average total outpatient cost was BDT 85.97 or US $\$ 1.10$ where medical and non-medical costs constituted 32.56 and $67.44 \%$ respectively. Medicine cost (BDT 28.16 or US $\$ 0.36$ ) was the main cost driver followed by the cost of space (BDT 26.20 or US $\$ 0.33$ ) and staff salaries (BDT 25.49 or US \$ 0.32). A lump sum amount of capital cost (BDT 4.84 or US \$ 0.06) was also incurred during the treatment course of outpatients (Table 5).

\section{Societal cost of illness}

The average total societal cost of illness per episode was BDT 5274.02 (US \$ 67.18) whereas average inpatient and outpatient costs were BDT 8675.09 (US \$ 110.51) and BDT 1853.96 (US \$ 23.62) respectively (Table 6). Among all of the cost segments, households cost contributed a larger portion ( $80 \%$ of the total costs) and

Table 4 Cost burden and catastrophic health expenditure in different socioeconomic condition

\begin{tabular}{|c|c|c|c|c|c|}
\hline \multirow[t]{2}{*}{ Income group } & \multirow[t]{2}{*}{$\begin{array}{l}\text { Direct cost as percentage of } \\
\text { monthly household income }\end{array}$} & \multicolumn{4}{|c|}{$\begin{array}{l}\text { Percentage of household spending for healthcare expenditure as a share } \\
\text { of monthly household income }\end{array}$} \\
\hline & & $10 \%$ & $15 \%$ & $20 \%$ & $25 \%$ \\
\hline Poorest quintile $(\leq 10,000)$ & $\begin{array}{l}21.45 \% \\
(17.32 \%-25.58 \%)\end{array}$ & $\begin{array}{l}49.20 \% \\
(43.66 \%-54.75 \%)\end{array}$ & $\begin{array}{l}40.51 \% \\
(35.18 \%-46.08 \%)\end{array}$ & $\begin{array}{l}31.83 \% \\
(26.88 \%-37.23 \%)\end{array}$ & $\begin{array}{l}27.01 \% \\
(22.35 \%-32.23 \%)\end{array}$ \\
\hline $\begin{array}{l}\text { 2nd quintile } \\
(10,001-12,000)\end{array}$ & $\begin{array}{l}11.6 \% \\
(9.18 \%-14.02 \%)\end{array}$ & $\begin{array}{l}39.64 \% \\
(30.94 \%-49.05 \%)\end{array}$ & $\begin{array}{l}26.13 \% \\
(18.77 \%-35.12 \%)\end{array}$ & $\begin{array}{l}16.22 \% \\
(10.43 \%-24.33 \%)\end{array}$ & $\begin{array}{l}9.91 \% \\
(5.55 \%-17.06 \%)\end{array}$ \\
\hline $\begin{array}{l}\text { 3rd quintile } \\
(12,001-18,000)\end{array}$ & $\begin{array}{l}9.35 \% \\
(7.92 \%-10.79 \%)\end{array}$ & $\begin{array}{l}31.84 \% \\
(26.04 \%-38.26 \%)\end{array}$ & $\begin{array}{l}16.14 \% \\
(11.86 \%-21.59 \%)\end{array}$ & $\begin{array}{l}10.31 \% \\
(6.94 \%-15.06 \%)\end{array}$ & $\begin{array}{l}7.17 \% \\
(4.43 \%-11.41 \%)\end{array}$ \\
\hline $\begin{array}{l}\text { 4th quintile } \\
(18,001-30,000)\end{array}$ & $\begin{array}{l}6.45 \% \\
(5.27 \%-7.64 \%)\end{array}$ & $\begin{array}{l}20.62 \% \\
(16.10 \%-26.02 \%)\end{array}$ & $\begin{array}{l}10.12 \% \\
(6.97 \%-14.46 \%)\end{array}$ & $\begin{array}{l}5.84 \% \\
(3.54 \%-9.47 \%)\end{array}$ & $\begin{array}{l}2.33 \% \\
(1.05 \%-5.11 \%)\end{array}$ \\
\hline $\begin{array}{l}\text { Upper quintile } \\
(30,000+)\end{array}$ & $\begin{array}{l}4.21 \% \\
(3.34 \%-5.08 \%)\end{array}$ & $\begin{array}{l}8.22 \% \\
(4.71 \%-13.95 \%)\end{array}$ & $\begin{array}{l}4.79 \% \\
(2.29 \%-9.75 \%)\end{array}$ & $\begin{array}{l}4.11 \% \\
(1.85 \%-8.87 \%)\end{array}$ & $\begin{array}{l}1.37 \% \\
(0.34 \%-5.34 \%)\end{array}$ \\
\hline Overall & $\begin{array}{l}11.75 \% \\
(10.37 \%-13.14 \%)\end{array}$ & $\begin{array}{l}31.77 \% \\
(29.02 \%-34.66 \%)\end{array}$ & $\begin{array}{l}21.37 \% \\
(18.99 \%-23.97 \%)\end{array}$ & $\begin{array}{l}15.36 \% \\
(13.30 \%-17.68 \%)\end{array}$ & $\begin{array}{l}11.35 \% \\
(9.57 \%-13.43 \%)\end{array}$ \\
\hline Rich-poor ratio & 0.196 & 0.167 & 0.118 & 0.129 & 0.051 \\
\hline Rich-poor difference & -17.240 & -40.980 & -35.720 & -27.720 & -25.640 \\
\hline
\end{tabular}




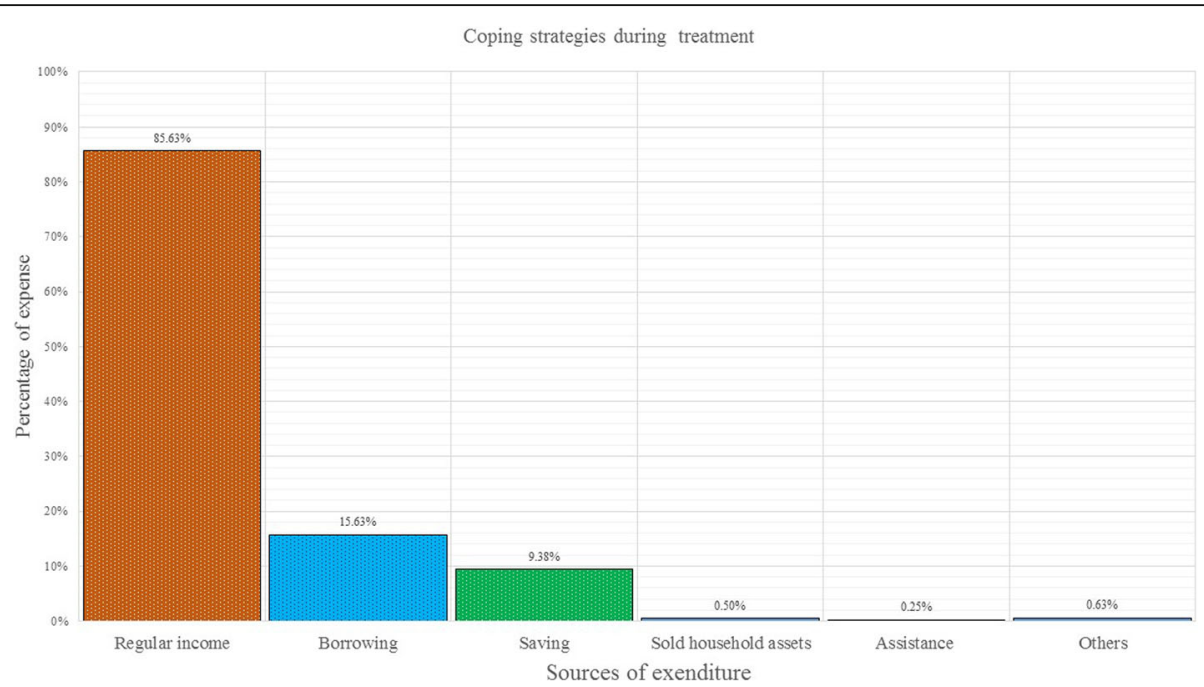

Fig. 1 Coping mechanisms during diarrheal treatment

OOP contributed $32 \%$ of the total societal cost of illness. Considering the provider actual treatment cost, the nonmedical cost (19.66\%) was the main cost driver. However, among all of the cost components, the indirect cost of patients and caregivers (BDT 2490 or US \$ 31.72) was the main cost driver of all types of care which is not apparent if only provider costs are measured.

\section{Annual economic burden}

In the light of the earlier findings this section expresses the overall economic burden of diarrhea in Bangladesh. According to the latest national health bulletin, approximately 2.56 million diarrheal cases and 24 deaths were reported in 2015 in various health facilities in Bangladesh [47]. During the hospital based survey, approximately $44 \%$ of the diarrheal patients received inpatient hospital care, and $66 \%$ had outpatient services.
The total annual cost of treatment was US\$ 172.02 million for societal perspective while US\$ 35.72 million was incurred by the health facilities.

\section{Discussion}

Diarrheal disease is a major public health concern associated with significant morbidity and mortality and economic loss in many societies. While the cost of illness for other infectious diseases in Bangladesh has been investigated [38, 48], knowledge of the cost of illness of diarrheal disease considering the broader societal perspective is limited. The current standards for cost-effectiveness analysis recommend to use a broader societal perspective considering both the provider and household perspective [33].

We found the average length of the diarrheal episode is 5 days (results not presented here) which incurred an average cost of BDT 5274.02 (US \$ 67.18) that could be

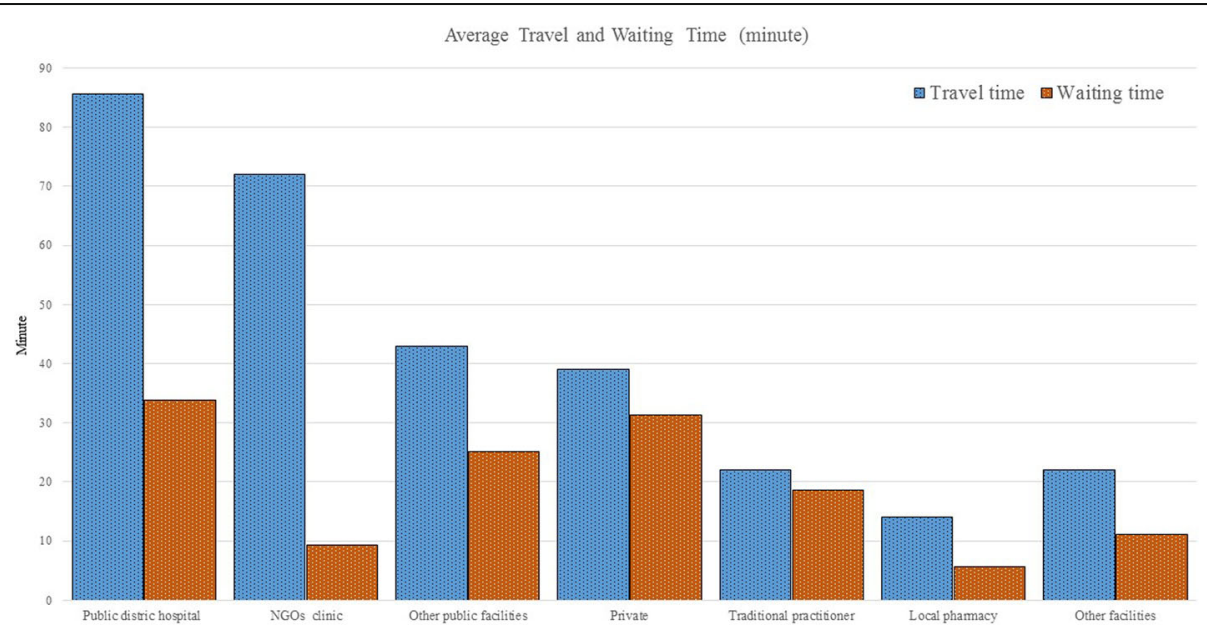

Fig. 2 Average travel and waiting time for receiving care 
Table 5 Distribution of provider costs: average inpatient vs outpatient's cost, BDT (US \$)

\begin{tabular}{|c|c|c|c|c|c|}
\hline \multirow[t]{2}{*}{ Cost } & \multirow[t]{2}{*}{ Parameters } & \multicolumn{2}{|c|}{ Inpatient $(N=402)$} & \multicolumn{2}{|c|}{ Outpatient $(N=399)$} \\
\hline & & Amount & $\%$ of total cost & Amount & $\%$ of total cost \\
\hline \multirow[t]{3}{*}{ Direct Medical } & Medicines & $83.23(1.06)$ & - & $28.16(0.36)$ & - \\
\hline & Diagnosis & - & - & - & - \\
\hline & Disposable items & $5.03(0.06)$ & - & - & - \\
\hline \multicolumn{2}{|l|}{ Total Direct Medical } & $88.27(1.12)$ & $4.18 \%$ & $28.16(0.36)$ & $32.56 \%$ \\
\hline \multirow[t]{12}{*}{ Direct Non-Medical } & Staff salaries & 836.38 (10.65) & - & $25.49(0.32)$ & - \\
\hline & Transport & $31.39(0.4)$ & - & - & - \\
\hline & Food & $323.25(4.12)$ & - & - & - \\
\hline & Stationery & $3.44(0.04)$ & - & $0.1(-)$ & - \\
\hline & Window shade & $1.21(0.02)$ & - & $0.03(-)$ & - \\
\hline & Electricity & $9.96(0.13)$ & - & $0.27(-)$ & - \\
\hline & Gas bill & $0.33(-)$ & - & $0.01(-)$ & - \\
\hline & Water bill & $0.01(-)$ & - & - & - \\
\hline & Telephone bill & $0.14(-)$ & - & - & - \\
\hline & Other Misallocations & $31.66(0.4)$ & - & $0.85(0.01)$ & - \\
\hline & Capital items & $456.31(5.81)$ & - & $4.84(0.06)$ & - \\
\hline & Building & $321.74(4.1)$ & - & $26.2(0.33)$ & - \\
\hline \multicolumn{2}{|c|}{ Total Direct Non-Medical } & $2015.82(25.68)$ & $95.82 \%$ & $57.8(0.74)$ & $67.44 \%$ \\
\hline \multicolumn{2}{|c|}{ Average cost per Patient } & $2104.09(26.80)$ & $100 \%$ & $85.97(1.1)$ & $100 \%$ \\
\hline
\end{tabular}

saved if the diarrheal disease was prevented. More than $52 \%$ of the total costs are the direct costs borne by the households (31\%) and hospitals (21\%) as the public hospitals are highly subsidised in Bangladesh [49]. In early 2001, Ali et al. found that the provider cost per day for the management of inpatient and outpatient in a district hospital (Manikgonj) near Dhaka city was BDT 317.27 or US \$ 4.04 and BDT 53.74 or US \$ 0.69 respectively [28]. Das et el estimated that the average inflation adjusted diarrheal treatment cost for under 5 year old children in rural Bangladesh was US \$ 6.99 though they did not consider the laboratory cost borne by the hospitals as well as the income loss of the household [29]. From a multi-country analysis, Rheingans et al. found that the

Table 6 Societal cost of illness due to diarrheal disease, BDT (US\$)

\begin{tabular}{|c|c|c|c|c|}
\hline Type of care & Perspective & Types of cost & Amount BDT (US\$) & Proportion of total cost (patients) \\
\hline \multirow[t]{5}{*}{ Inpatient Care $(n=402)$} & \multirow[t]{2}{*}{ Provider } & Direct medical & $88.27(1.12)$ & 1.02 \\
\hline & & Direct non-medical & $2015.82(25.68)$ & 23.24 \\
\hline & \multirow[t]{2}{*}{ Household } & Out of pocket payment & $2760(35.36)$ & 31.82 \\
\hline & & Indirect cost & $3811(48.55)$ & 43.93 \\
\hline & Societal & All costs & $8675.09(110.51)$ & $100 \%$ \\
\hline \multirow[t]{5}{*}{ Outpatient Care $(n=399)$} & \multirow[t]{2}{*}{ Provider } & Direct medical & $28.16(0.36)$ & 1.52 \\
\hline & & Direct non-medical & $57.8(0.74)$ & 3.12 \\
\hline & \multirow[t]{2}{*}{ Household } & Out of pocket payment & $609(7.76)$ & 32.85 \\
\hline & & Indirect cost & $1159(14.76)$ & 62.51 \\
\hline & Societal & All costs & $1853.96(23.62)$ & $100 \%$ \\
\hline \multirow[t]{5}{*}{ All- patient Care $(N=801)$} & \multirow[t]{2}{*}{ Provider } & Direct medical & $58.21(0.74)$ & 1.1 \\
\hline & & Direct non-medical & $1036.81(13.21)$ & 19.66 \\
\hline & \multirow[t]{2}{*}{ Household } & Out of pocket payment & $1689(21.51)$ & 32.02 \\
\hline & & Indirect cost & $2490(31.72)$ & 47.21 \\
\hline & Societal & All costs & $5274.02(67.18)$ & $100 \%$ \\
\hline
\end{tabular}


average household treatment cost for childhood diarrhoa was US \$ 1.82 where direct cost and indirect costs constituted US \$ 1.19 and US \$ 0.63 respectively in Bangladesh. The limitations of this study was the relatively small sample size and therefore was not representative of the country and that the study was conducted in a surveillance area [30]. An urban slum based study carried out in Bangladesh where the incidence of diarrhea is high and found that the cost of childhood diarrhea per episode ranged from BDT 124 (US \$ 1.81) to BDT 276 (US\$ 4.00) with an average duration of 3.76 days of diarrhea [31]. However, all of these studies did not consider the societal perspective and our study expresses a more complete accounting of all the relevant costs associated with an episode of diarrhea.

The current study found that the societal cost of illness per episode was US \$ 110.51 for inpatients and US \$ 23.6 for outpatients respectively. Recently, similar findings have been observed in a number of LMI countries. Aikins et al. in northern Ghana found that from the health sector perspectives, the average inpatient and outpatient treatment costs were US \$ 97.40 and the US \$ 4.10 respectively [50]. In Rwanda, the treatment cost per diarrheal hospitalization was US $\$ 101$ and $65 \%$ of this cost was borne by households [51]. Another study conducted in several hospitals in Vietnam found that the average treatment cost per episode was US\$ 106.9 whereas indirect costs made up the largest share (51.3\%) followed by the direct medical costs $(33.8 \%)$ and direct non-medical costs (14.9\%) [52]. The current study estimated the possible costs of providers (both medical and non-medical) and costs borne by the patients and their caregivers (both direct and productivity loss) in a standard hospital-based survey of six district hospitals of each six divisions in Bangladesh.

The study showed that the treatment cost for outpatients is lower than for inpatients. Although this study did not capture the cause of treatment-seeking behaviour, systemic literature review on the etiology of diarrhea, Walker et al. found ETEC and $V$ cholerae O1/ O139 to be the most frequently isolated pathogens in inpatients, whereas in the outpatient setting, salmonella sp., shigella sp., and E histolytica were commonly found [53]. Several studies conducted in Bangladesh to isolate pathogens from diarrheal stools found shigella sp. in outpatients. However, different types of pathogens such as salmonella sp., shigella sp., ETEC and $V$ cholerae O1/ O139, rotavirus, giardia, E histolytica, $V$ parahaemolytica and campylobacter were typically found in the inpatient setting [54-56]. Further studies are therefore required to better understand these findings.

Among all patients, adults with diarrhea consumed significantly more resources than the young which is consistent with earlier findings that high healthcare expenditure is associated with increase in age [57]. Diarrheal cost burden was significantly higher for the poorest than richest households. The main treatment coping mechanisms was the income of the households which was the only source of household's income. However, the highest cost burden (21.45\%) was observed for poorest quintile than richest (4.21\%). Considering the provider cost of treatment, the main cost driver was staff salaries (operating expenditure) and the cost of capital including building cost (investment cost). Some of those investment costs occurred at the beginning of the program and are often not listed in accounts or budget of the hospitals but nevertheless we consider that they are real costs and should be accounted for [35].

We estimate the annual economic burden of diarrheal diseases to be US \$ 172.02 million which was $12.28 \%$ of the total health expenditure in Bangladesh [58]. However, the estimation is based on the reported cases from health facilities although it is very common that diarrhea is inadequately managed at household level and is associated with high morbidity and mortality. In that sense, we underestimated the actual burden of diarrheal disease in Bangladesh. However, the study was unable to compare the total annual economic burden of diarrheal disease with other settings, however, a literature review of economic burden of rotavirus disease study in Asian settings showed that the annual economic burden of rotavirus illness laid between US\$ 0.41 million (Uzbekistan) up to US \$ 365 million in China [59], while the annual economic burden of rotavirus exceeds US \$ 72 million in India [60]. An unpublished estimation showed that approximately US\$ 7.06 million could be saved by preventing rotavirus diseases in Bangladesh [61]. The latest estimate of the annual GDP per capita in Bangladesh (2016) was US 1466 which indicated that approximately $4.58 \%$ of GDP per capita spent on treating each diarrheal episode which might be a critical concern as it is the prime cause of hospital admission in Bangladesh [17, 62]. Therefore, by controlling diarrheal diseases huge amounts of resources would be saved. Consequently with reduced number of patients, hospitals could save extra resources like hospital bed, space, doctor's time, and other resources that could be channeled for other purposes. During the treatment, reliance on OOP expenditures leads to catastrophic economic burden for many households. Further, many poor and vulnerable people cannot afford healthcare as currently there are no social health protection schemes in Bangladesh. To reduce financial barriers to healthcare for the needy and to avoid catastrophic health expenditures, social health protection might be an option which is the core theme of universal health coverage.

The limitations to this study include the design; as a cross-sectional study, it was not possible to estimate the cost variation in light of seasonality such as the 
incidence of usual peaks during the hot and winter seasons in Bangladesh [63]. The treatment of diarrheal disease relies heavily on households' treatment patterns and resources which are not covered in this study [50]. The current study was conducted among hospitalized patients, but many diarrheal episodes occurred in the community which is not captured in this study. The other limitation was the sample size as only selected hospitals were considered, albeit on a randomised basis, and therefore the study might not be representative of the whole country. We did not collect the information about severity of diarrheal illness directly, though patients with severe disease are more likely to be inpatients that outpatients [64].

\section{Conclusions}

In LMI countries like Bangladesh, diarrheal diseases continue to be an overwhelming problem. Cost analysis of diarrheal diseases is required for estimating resources for managing and preventing diarrheal disease. Therefore, the economic impact of any public health interventions (either preventive or promotive) that can reduce the prevalence of diarrheal diseases can be estimated from the data generated from this study.

\section{Abbreviations}

ANOVA: Analysis of Variance; BDT: Bangladeshi Taka; HH: Households; HRD: Hospital Records Departments; LMI: Lower and Middle Income; NGOs: Non-Governmental Organisations; OOP: Out-of-Pocket; OOPP: Out-ofPocket Payment; US\$: United State Doller; WHO: World Health Organization

\section{Acknowledgements}

icddr,b acknowledges with gratitude the commitment of the SIDA unrestricted fund to its research efforts. Icddr,b is thankful to the Governments of Australia, Bangladesh, Canada, Sweden, and the UK for providing core/ unrestricted support. The authors gratefully acknowledge the University of Strathclyde PhD scholarship for its research effort. The authors would also like to thank the health economics and financing research groups for their comments on an earlier draft of the manuscript.

\section{Funding}

The project is a part of the SIDA young investigator award.

\section{Availability of data and materials}

All data described in the study can be provided for free by contact with the corresponding author.

\section{Authors' contributions}

ARS, MS, TMH, MSU, SH, HR, ZI, JAM conceived and designed the study. ARS, MS, RAM, NA, JAM, RVM am AM performed the field experiments and analyzed the data. ARS, MS, RAM, RVM am AM prepared the first version of the manuscript. ARS, MS, RAM, NA, TMH, MSU, SH, HR, ZI, JAM, RVM, AM revised and finalized the manuscript. All authors read and approved the final version of the manuscript.

\section{Ethics approval and consent to participate}

A written informed consent was obtained from all respondents before the data collection.

\section{Consent for publication}

Not applicable.

\section{Competing interests}

The authors declare that they have no competing interests.

\section{Author details}

${ }^{1}$ International Centre for Diarrhoeal Disease Research, Bangladesh (icddr,b), Dhaka, Bangladesh. ${ }^{2}$ University of Strathclyde, Glasgow, UK. ${ }^{3}$ Sydney School of Public Health, Sydney Medical School, The University of Sydney, Sydney, Australia. ${ }^{4}$ Institute of Epidemiology, Disease Control and Research, Dhaka, Bangladesh. ${ }^{5}$ Health Economics Unit, Ministry of Health and Family Welfare, Dhaka, Bangladesh. ${ }^{6}$ Liverpool School of Tropical Medicine, Liverpool, UK.

Received: 13 July 2017 Accepted: 11 December 2017

Published online: 05 January 2018

\section{References}

1. Vos T, Allen C, Arora M, Barber RM, Bhutta ZA, Brown A, et al. Global, regional, and national incidence, prevalence, and years lived with disability for 310 diseases and injuries, 1990-2015: a systematic analysis for the global burden of disease study 2015. Lancet. 2016;388:1545-602.

2. Liu L, Oza S, Hogan D, Chu Y, Perin J, Zhu J, et al. Global, regional, and national causes of under-5 mortality in 2000-15: an updated systematic analysis with implications for the sustainable development goals. Lancet. 2016:388:3027-35

3. Mashoto KO, Malebo HM, Msisiri E, Peter E. Prevalence, one week incidence and knowledge on causes of diarrhea: household survey of under-fives and adults in Mkuranga district, Tanzania. BMC Public Health. 2014;14:985.

4. National Institute of Population Research and Training, Mitra and Associates and II. Bangladesh Demographic and Health Survey 2014: Key Indicators. Dhaka, Bangladesh; 2015.

5. Montgomery $\mathrm{M}$, Elimelech $\mathrm{M}$. Water and sanitation in developing countries: including health in the equation. Env. Sci Technol. 2007;41:17-24.

6. Schwartz BS, Harris JB, Khan Al, LaRocque RC, Sack DA, Malek MA, et al. Diarrheal epidemics in Dhaka, Bangladesh, during three consecutive floods: 1988, 1998, and 2004. Am J Trop Med Hyg. 2006;74:1067-73.

7. Rahman KM, Duggal P, Harris JB, Saha SK, Streatfield PK, Ryan ET, et al. Familial aggregation of vibrio cholerae-associated infection in Matlab, Bangladesh. J Health Popul Nutr. 2009;27:733-8.

8. Colombara DV, Faruque ASG, Cowgill KD, Mayer JD. Risk factors for diarrhea hospitalization in Bangladesh, 2000-2008: a case-case study of cholera and shigellosis. BMC Infect Dis. 2014;14:440.

9. Ali M, Emch M, Donnay JP, Yunus M, Sack RB. Identifying environmental risk factors for endemic cholera: a raster GIS approach. Heal Place. 2002:8:201-10.

10. Biswas DK, Bhunia R, Maji D, Das P. Contaminated pond water favors cholera outbreak at Haibatpur Village, Purba Medinipur District, West Bengal, India. J Trop Med Hindawi Publishing Corporation; 2014;2014.

11. You YA, Ali M, Kanungo S, Sah B, Manna B, Puri M, et al. Risk map of cholera infection for vaccine deployment: the eastern Kolkata case. PLoS One. 2013;8

12. Drasar BS, Tomkins AM, Feacham RG. Seasonal aspects of diarrhoeal disease. Seas. Dimens. to Rural poverty. (Report to UK Overseas Dev. Assoc. London Sch. Hyg. Trop. Med. London. London, UK; 1978.

13. Black RE, Lanata CF. Epidemiology of diarrhoeal diseases in developing countries. Infect. Gastrointest. tract. Blaser MJ, Smith PD, Ravdin Jl, Greenb. HP, Guerr. Rl, eds. Ra. New York: Raven Press, New York; 1995.

14. Ozguler M. Febril Neutropenia: an approach as an infectious disease specialist. USA: Scientific Research Publishing, Inc; 2015. Available from: https://books.google.co.in/books?hl=en\&lr=\&id=1tY4CwAAQBAJ\&oi= fnd\&pg=PP1\&dq=Febrile+Neutropenia:+An+Approach+as+an+Infectious +Disease+Specialist.+Scientific+research+publishing\&ots=ODe_BITVTH\&sig= FSnRPUSNjMnEeFU.

15. Rabbani GH, Larson CP, Islam R, Saha UR, Kabir A. Green bananasupplemented diet in the home management of acute and prolonged diarrhoea in children: a community-based trial in rural Bangladesh. Tropical Med Int Health. 2010;15:1132-9.

16. Isanaka S. Systematic review of diarrhea duration and severity in children and adults in low- and middle-income countries. BMC Public Health [Internet]. BioMed Central Ltd; 2012;12:832.

17. Sultana M, Mahumud RA, Sarker AR. Emerging patterns of mortality and morbidity in district level hospitals in Bangladesh. Ann Public Heal Res. 2015;2:2-4.

18. Shillcutt SD, Lefevre AE, Walker CLF, Taneja S, Black RE, Mazumder S. Economic costs to caregivers of diarrhoea treatment among children below 5 in rural Gujarat India : findings from an external evaluation of the DAZT programme. Health Policy Plan. 2016;31:1411-22. 
19. Burke R, Rebolledo P, Embrey S, Wagner L, Cowden C. The burden of pediatric diarrhea: a cross-sectional study of incurred costs and perceptions of cost among Bolivian families. BMC Public Health. 2013;13

20. Kosek M, Bern C, Guerrant RL. The global burden of diarrhoeal disease, as estimated from studies published between 1992 and 2000. Bull World Health Organ. 2003;81:197-204.

21. Bartsch SM, Lee BY. Economics and financing of vaccines for diarrheal diseases. Hum Vaccin Immunother. 2014;10:1568-81.

22. Macintyre U, Villiers F. Economic burden of diarrheal disease in a tertiary level hospital, Gauteng, South Africa. J Infect Dis. 2010;202:116-25.

23. Burke R, Rebolledo P, Embrey S, Wagner L, Cowden CL, Kelly FM, et al. The burden of pediatric diarrhea: a cross-sectional study of incurred costs and perceptions of cost among Bolivian families. BMC Public Health. 2013;13

24. Bhuiyan MU, Luby SP, Zaman RU, Rahman MW, Sharker MA, Hossain MJ, et al. Incidence of and risk factors for hospital-acquired diarrhea in three tertiary care public hospitals in Bangladesh. Am J Trop Med Hyg. 2014;91:165-72.

25. Pham-Duc P, Nguyen-Viet H, Hattendorf J, Cam PD, Zurbrügg C, Zinsstag J, et al. Diarrhoeal diseases among adult population in an agricultural community Hanam province, Vietnam, with high wastewater and excreta re-use. BMC Public Health. 2014;14:978.

26. Konstantyner T, Cláudia T, De Oliveira R, Mais L, Warkentin S. Prevalence and hospitalization rates due to diarrhoea in infants : the 2006 Brazilian National Demographic Health Survey. J Epidemiol Res. 2016;2:29-38.

27. Parashar UD, Bresee JS, Glass RI. The global burden of diarrhoeal disease in children. Bull World Health Organ. 2003:81:236.

28. Ali Q. Calculation of total unit cost for diarrhoeal management at district and Thana health complex. 2001

29. Das J, Das SK, Ahmed S, Ferdous F, Farzana FD, Sarker MHR, et al. Determinants of percent expenditure of household income due to childhood diarrhoea in rural Bangladesh. Epidemiol Infect. 2015:1-7.

30. Rheingans R, Kukla M, Faruque ASG, Sur D, Zaidi AKM, Nasrin D, et al. Determinants of household costs associated with childhood diarrhea in 3 south Asian settings. Clin Infect Dis. 2012;55:327-35.

31. Jahangir A. Prevalence and Costs of Childhood Diarrhoea in the Slums of Dhaka. Kathmandu, Nepal; 2009. Report No.: 46-09.

32. Siegel JE, Weinstein MC, Russell LB, Gold MR. Recommendations for reporting cost-effectiveness analyses. JAMA. J Am Med Assoc. 1996; 276:1339-41.

33. Gold MR, Siegel JE, Russell LB, Weinstein MC. Cost- effectiveness in health and medicine. New York: Oxford University Press; 1996

34. WHO. Guidelines for estimating the economic burden of diarrhoeal disease with focus on assessing the costs of rotavirus diarrhoea. Geneva, Switzerland: Department of Immunization, Vaccines and Biologicals; 2005.

35. Drummond MF, Sculpher MJ, Torrance GG, O'Brien BJ, Stoddart G. Methods for the economic evaluation of health care Programmes. Third. Oxford Univ. press. York. New York: Oxford University Press; 2005.

36. Rice DP. Estimating cost of illness. US Dep. Heal. Educ. Welfare, Public Heal. Serv. 1966;

37. van Roijen L, Essink-Bot ML, Koopmanschap MA, Bonsel G, Rutten FF. Labor and health status in economic evaluation of health care. The health and labor questionnaire. Int J Technol Assess Health Care. 1996;12:405-15.

38. Sarker AR, Islam Z, Khan IA, Saha A, Chowdhury F, Khan Al, et al. Cost of illness for cholera in a high risk urban area in Bangladesh: an analysis from household perspective. BMC Infect Dis. 2013;13:518.

39. Poulos C, Riewpaiboon A, Stewart JF, Clemens J, Guh S, Agtini M, et al. Costs of illness due to endemic cholera. Epidemiol Infect. 2012;140:500-9.

40. Chima Rl, Goodman CA, Mills A. The economic impact of malaria in Africa: a critical review of the evidence. Health Policy (New York). 2003;63:17-36.

41. Grietens KP, Boock AU, Peeters H, Hausmann-Muela S, Toomer E, Ribera JM. "It is me who endures but my family that suffers": social isolation as a consequence of the household cost burden of buruli ulcer free of charge hospital treatment. PLoS Negl Trop Dis. 2008;2:1-7.

42. GOB. MONTHLY REPORT ON FISCAL- MACRO POSITION [Internet]. Dhaka, Bangladesh; 2016. Available from: http://www.mof.gov.bd/en/budget/ $\mathrm{mfmu} / \mathrm{mfmu}$ February_16.pdf.

43. Javanbakht M, Mashayekhi A, Haghdoost A, Khamesh M, Kharazmi E, Sadeghi A, et al. Cost of illness analysis of type 2 diabetes mellitus in Iran. PLoS One. 2011;6

44. Coduras A, Rabasa I, Frank A, Bermejo-Pareja F, López-Pousa S, López-Arrieta $\mathrm{JM}$, et al. Prospective one-year cost-of-illness study in a cohort of patients with dementia of Alzheimer's disease type in Spain: the ECO study. J Alzheimers Dis. 2010;19:601-15.

45. Coduras A, Rabasa I, Frank A, Bermejo-Pareja F, López-Pousa S, López-Arrieta $J M$, et al. Prospective one year cost of illness study in a cohort of patients with dementia of Alzheimer's disease type in Spain: the eco study. J Alzheimers Dis. 2010;19:601-15.

46. Carl FB. Diarrhoea case management in low- and middle-income countries. An unfinished agenda. Bull World Health Organ. 2007;85:42-8.

47. MOHFW. Health bulletin 2016. Dhaka: Bangladesh; 2016. Available from: www.dghs.gov.bd.

48. Alamgir NI, Naheed A, Luby SP, Brooks W, Breiman R, Goswami D, et al. Coping strategies for financial burdens in families with childhood pneumonia in Bangladesh. BMC Public Health. 2010;10:622.

49. Andaleeb SS. Public and private hospitals in Bangladesh: service quality and predictors of hospital choice. Health Policy Plan. 2000;15:95-102.

50. Aikins M, Armah G, Akazili J, Hodgson A. Hospital health care cost of diarrheal disease in northern Ghana. J Infect Dis. 2010;202 Suppl:S126-30.

51. Ngabo F, Mvundura M, Gazley L, Gatera M, Rugambwa C, Kayonga E, et al. The economic burden attributable to a child's inpatient admission for diarrheal disease in Rwanda. PLoS One. 2016:11:1-16.

52. Hoang VM, Tran TA, Ha AD, Nguyen VH. Cost of hospitalization for foodborne diarrhea: a case study from Vietnam. J Korean Med Sci. 2015;30: S178-82.

53. Fischer Walker $C L$, Sack D, Black RE. Etiology of diarrhea in older children, adolescents and adults: a systematic review. PLoS Negl Trop Dis. 2010;4

54. Baqui A, Yunus M, Zaman K, Mitra A, Hossain K. Surveillance of patients attending a rural diarrhoea treatment centre in Bangladesh. Trop Geogr Med. 1991:43:17-22.

55. Hossain MA, Albert MJ, Hasan KZ. Epidemiology of shigellosis in Teknaf, a coastal area of Bangladesh: a 10-year survey. Epidemiol Infect. 1990;105:41-9.

56. Oberle M, Merson M, Islam M, Rahman A. Diarrhoeal Disease in Bangladesh Epidemiology, Mortality Averted and Costs at a Rural Treatment Centre. Int J [Internet]. 1980;9.

57. Sarker AR, Mahumud RA, Sultana M, Ahmed S, Ahmed W, Khan JA. The impact of age and sex on healthcare expenditure of households in Bangladesh. Springerplus [Internet]. 2014 [cited 2014 Oct 21];3:435.

58. Ministry of Health and Family Welfare. Bangladesh National Health Accounts 1997-2012 [Internet]. Dhaka, Bangladesh; 2015. Available from: http://www. heu.gov.bd/pdf/summary.bnha\%201997-2012.pdf.

59. Kawai K, O'Brien MA, Goveia MG, Mast TC, El Khoury AC. Burden of rotavirus gastroenteritis and distribution of rotavirus strains in Asia: a systematic review. Vaccine. Elsevier Ltd; 2012;30:1244-1254.

60. Tate JE, Chitambar S, Esposito DH, Sarkar R, Gladstone B, Ramani S, et al. Disease and economic burden of rotavirus diarrhoea in India. Vaccine. 2009;27

61. Sarker AR, Sultana M, Mahumud RA, Meer R Van Der, Morton A, Sarker AR Cost-effectiveness analysis of introducing universal childhood rotavirus vaccination in Bangladesh Cost-effectiveness analysis of introducing universal childhood rotavirus vaccination in Bangladesh. Hum. Vaccin. Immunother. [Internet]. Taylor \& Francis; 2017;Accepted:1-10. Available from: https://doi.org/10.1080/21645515.2017.1356962.

62. Independent Online Desk. GDP growth $7.05 \%$ in current fiscal year. Indep. [Internet]. Dhaka, Bangladesh; 2016 Apr 5; Available from: http://www. theindependentbd.com/post/39661.

63. Das SK, Begum D, Ahmed S, Ferdous F, Farzana FD, Chisti MJ, et al. Geographical diversity in seasonality of major diarrhoeal pathogens in Bangladesh observed between 2010 and 2012. Epidemiol Infect. 2014; 142:2530-41.

64. Das SK, Nasrin D, Ahmed S, Wu Y, Ferdous F, Farzana FD, et al. Health careseeking behavior for childhood diarrhea in Mirzapur, rural Bangladesh. Am J Trop Med Hyg. 2013;89:62-8. 